\title{
Preface to the Special Issue: Friction Stir Welding and Processing
}

\author{
Z. Y. $\mathrm{Ma}^{1}$
}

Published online: 25 January 2020

(c) The Chinese Society for Metals (CSM) and Springer-Verlag GmbH Germany, part of Springer Nature 2020

Friction stir welding (FSW), a highly efficient solid-state joining technique, was invented at The Welding Institute, UK, in 1991. Utilizing frictional and adiabatic heating, plastic deformation and solid-state diffusion, FSW has been widely accepted as a "green" welding technology owing to its energy efficiency and environment friendliness. Now, FSW has achieved broad application in various industries, such as aerospace and transportation, and is considered the most significant development in the field of material joining over the past two decades. Friction stir processing (FSP), later developed based on the fundamental principles of FSW, has been demonstrated as an effective and versatile metalworking technique for modifying and fabricating metallic materials.

With the development of FSW/FSP and their significant commercial success in aluminum alloys, FSW has been applied to the welding of high melting-point materials and difficult-to-weld materials, such as steels, titanium alloys, and metal matrix composites. Furthermore, friction stir spot welding (FSSW) and bobbin tool FSW have been developed to satisfy certain special welding requirements. However, these developments not only pose a critical challenge to the applicability and durability of welding tools, but also increase the difficulty of understanding the underlying mechanisms responsible for microstructural evolutions during these processes.

As a fully coupled thermo-mechanical process, material flow and microstructural evolution during FSW/FSP are quite complex. To advance FSW/FSP from academic research into broader industrial applications, the discrepancy between the understanding of these intricacies of the friction stir process and the pace of industrial applications, especially for FSW/FSP of high melting-point materials and difficult-to-weld materials as well as for FSSW and bobbin tool FSW, needs to be addressed through the collection of a variety of performance and property data, which will require significant research and development activities.

In this special issue, the recent processing, microstructures, and performance advances in FSW/FSP will be reported, with the intent of developing deeper understanding of the friction stir process and its critical influencing factors. Sixteen insightful papers authored by some of the leading researchers in this area have been accepted for final publication in this issue.

Among these papers, four invited review articles authored by Wang et al., Feng et al., Chen et al., and Wang et al. carefully address the development of bobbin tool FSW, refill FSSW, thermo-mechanical analysis of FSW, and FSP of magnesium alloys. In the research papers, FSW/FSP of aluminum alloys, magnesium alloys, steels, zirconium, metal matrix composites, dissimilar materials, as well as modeling were reported. The subjects of the papers cover the recent major focuses of FSW/FSP.

We sincerely thank all the authors for their noteworthy contributions and all the reviewers for their critical and constructive assessment. We also appreciate the significant assistance from the editors and the publishing team of Acta Metallurgica Sinica (English Letters) in organizing and publishing this special issue. We hope that this special issue will provide enjoyment to readers and inform them on the current state of the FSW/FSP field.

Guest Editor

Z. Y. Ma

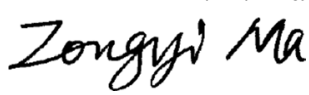

Available online at http://link.springer.com/journal/40195.

Z. Y. Ma

zyma@imr.ac.cn

1 Institute of Metal Research, Chinese Academy of Sciences, Shenyang, China 


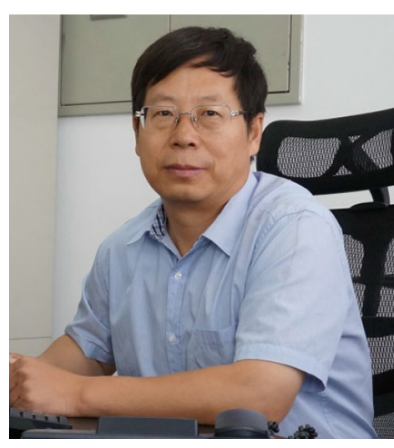

Dr. Z. Y. Ma is a Professor of Materials Science and Engineering at the Institute of Metal Research (IMR), Chinese Academy of Sciences. He currently serves as an editorial committee member of several journals, including Materials Science \& Engineering A, Science and Technology of Welding and Joining, Materials Characterization, Journal of Materials Science \& Technology, Acta Metallurgica Sinica (English Letters),

Science China Materials, etc. Dr. Ma's research mainly focuses on friction stir welding and processing (FSW/FSP), metal matrix composites, and high-temperature deformation behavior of materials. Dr. Ma is an internationally recognized leader in the fields of FSW/FSP. He developed new fabrication methods of surface composites and nanocomposites based on FSP, established a new "FSP + aging" route to enhance the mechanical properties of cast magnesium alloys, proposed the heat source zone-isothermal dissolution layer (HSZ-IDL) model in which welding speed was identified as the key factor determining the tensile strength of FSW joints of precipitation-strengthened aluminum alloys and composites, and developed wear-resistant cermet welding tool and achieved FSW of aluminum matrix composites with equal strength to parent materials. Dr. Ma has published 320 peer-reviewed journal papers, with a total of over 14,000 citations based on the Web of Science, and a monograph titled "Friction Stir Superplasticity for Unitized Structures" in Elsevier. He has written several highly cited review papers, including "Friction stir welding and processing," Materials Science and Engineering-Reports, 2005, 50(1-2), 1-78; and "Friction stir processing technology-a review," Metallurgical and Materials Transaction A, 2008, 39(3) 642-658. Both review articles have attracted considerable attention as illustrated by their 3173 and 483 citations, respectively, searched from the Web of Science. The first review paper is currently the highest cited review paper in this area. Dr. Ma will continue to dedicate his research efforts toward further improvement and innovation in this field. 